\title{
The Output Gap and Potential Output in Namibia
}

\author{
Emmanuel Ziramba, Bernie Zaaruka, Johanna Mumangeni, Charlotte Tjeriko, Jaungura Kaune \\ Department of Economics, University of Namibia, Pionierspark, Windhoek, Namibia \\ zirambae@gmail.com
}

\begin{abstract}
The study analysed the behaviour of potential output and output gap for the Namibian economy using annual data from 1980 to 2016. The study employed the Hodrick-Prescott (HP) filter method and the production function approaches to estimate potential output before calculating the output gap. The results suggest an annual average growth rate of 3.6 percent in potential output. However, it has been noted that the average annual growth rate in potential output has been shifting during the period under review. In fact, the results suggest an annual average growth rate of 1.6 percent between 1980 and 1985 and an increase to 2.5 percent per year for the period 1986 to 1990. Potential output estimates obtained using the production function approach was smooth and stable throughout the study period. The potential output estimates obtained through the two methods follow the same cyclical movements. The output gap estimates from the two techniques are not different from each other, and they appear to move together.
\end{abstract}

Keywords: Output gap, Potential output, Namibia.

\section{Introduction}

An output gap is identified by the difference between an economy's actual output level and the level of production that would ensure full employment of its resources. An estimate of potential output at any point in time indicates the economy's capacity to supply goods and services. Output gap estimates can reflect the cyclical patterns an economy goes through over time. The output gap can give an early indication of underlying inflationary pressures within an economy (Njuguna et al., 2005). All things being equal, a positive output gap will result in inflation due to demand pressures in the goods markets. A negative output gap has been associated with deflationary pressures in an economy (Claus, 2000). A strong positive correlation between the growth rate of potential and actual output will not put pressure on prices. An ideal economy is thus one where the output gap is equal to zero.This signifies that an economy is operating efficiently. According to Jovicic (2017) potential output and output gap estimates provide indications of the business cycle position of an economy. Such information is useful to central banks in their economic analysis. Therefore, when demand exceeds potential output, the central bank will implement a contractionary policy to mitigate the inflation pressures. While when there is excess supply, the central bank will respond by implementing expansionary policies to boost demand. In Namibia, the economy has grown on average by 3.5 percent per annum for the past three decades yet the unemployment rate remains much higher than in other developing countries. The country's economy has grown by 3.5 percent per annum for the last four decades, whilst the broad unemployment rate has in fact grown to 34.0 percent in 2016 based on the Namibia Labour Force Survey (2016).

Thus, the potential output provides an indicator of the level of growth that is not inflationary. Despite macroeconomic stability and a single digit inflation rate, the unemployment rate keeps rising in the Namibian economy (Eita \& Ashipala, 2010). According to Eita and Ashipala (2010) Namibia's unemployment decreases as actual output increases towards its potential level a study by Kanyenze and Lapeyre (2012) showed that Namibia is facing a daunting structural unemployment and underemployment problem. This was confirmed by the Government of Namibia (2013) in the labour market trends. Unemployment rates were reported to be high among persons with primary and secondary school education. This type of unemployment tends to persist and becomes present even if an economy is at full employment. Full employment is normally defined as a situation where there is no cyclical unemployment.The main purpose of this study was to estimate potential output and output gap for Namibia. Two conventional methods were used to estimate potential output in Namibia. The output gap estimates were computed using the potential output estimates which were obtained from the production function approach. The remainder of the paper is organised as follows. Section 2 presents an overview of the conventional empirical review. Section 3 provides the methodology that was used. Section 4 presents the empirical estimates for potential output and the output gap. The conclusions are given in section 5. The results from the estimates show that the trade-off between economic activity and 
inflation is not as straightforward as theory suggests which is mainly due to once-off and country-specific factors.

\section{Literature Review}

Using quarterly data from 1999 to 2015, Kasabov et al. (2017) use several methods to assess the link between potential output and inflation in Bulgaria. The study used a macroeconomic model estimated with Bayesian methods and the Kalman filter to estimate a Phillips curve type relationship between output and inflation as well as produce estimates for output and unemployment gaps for Bulgaria. A large negative output gap was observed between the periods 1999to 2003, which corresponds to the high unemployment in that period. High inflation was also observed during the same period, which the authors attribute to the transition to market economy the country went through in terms of opening up borders to trade and privatization on. In a review by Huang and Luo (2017) on potential output and inflation dynamics they discovered that potential output declined substantially in the USA, after the recent global recession of 2008 and 2009. The study was employed four different techniques which included the HP filter, unobserved-component models, the Beveridge-Nelson decomposition and the neoclassical growth models. The results of the different techniques, with the exception of the neoclassical growth models, exhibit similar trends with minor deviations due to different assumptions. The neoclassical growth models suggested the least potential output loss during the period 2008 and 2009. The technique exhibited a huge negative gap over the sample period whilst the other measures suggested that output gap has been closed despite somewhat different historical estimates (Huang \& Luo, 2017).

Using four distinct time series filters, Fedderke and Mengisteab (2016) estimated the potential output for South Africa for the sample period 1960Q1 to 2015Q2. The filters which were used included the HP, Butterworth (BW), Christiano-Fitzgerald (CF) and Baxter-King (BK).Their results show that there was insignificant difference between the HP and BW (the two high-pass filters). The CF and BK filters (the two band-width filters), also showed insignificant difference in their results of the potential output. The study however, reported huge differences between the high-pass filters and the band. Consequently, the conclusions regarding the output gap depend on the choice of filters being used. South Africa's potential growth rate was estimated to range from 1.9-2.3 percent. Kloudova (2015) used quarterly data from 1995 to 2012 to estimate potential output and output gap for the Russian economy. The study used three methods to estimate output gap and potential output, namely the Hodrick-Prescott filter, production function and a Structural VAR model. All methods produced very similar output gap estimates. The output gap was used to forecast inflation. The study used two models to assess the relationship between inflation and the output gap in Russia. In the first model expressed both inflation and output gap in levels while the second employed rates of change in the variables. The results from both models indicated that the output gap is a good indicator for inflation in the Russian economy.

Jemec (2012) employed several statistical methods to estimate potential output gap for Slovenia for the period 1995q1 to 2012q2. The results from the different techniques showed that the output gap behaved the same way regardless of the technique used. Positive output gaps were observed for the periods of 1996-1997, 1999-2001 and 2006-2008, while negative output gaps were observed for all other periods. Total factor productivity (TFP) growth was found to be the leading source of growth in potential output before the 2008 global financial crisis. The contribution of capital was found to be relatively high prior to the global financial crisis and decreased significantly during the crisis. The labour contributed the least of all, and its contribution even turned negative during the global financial crisis. Using different techniques, in a similar study on Egypt, Shahin (2010) estimated potential output and output gap for the period 2003 to 2011. The author used various filtering methods as well as the production function approach to estimate the Egyptian potential output. The potential labour that was employed in the production function approach was obtained by deriving Egypt's non-accelerating-inflation rate of unemployment (NAIRU). The results from the production function and wavelets filter approaches were conflicting. The found the output gap to be negative output gap during the global financial crisis period, while the later showed the output gap to be positive output gap, following the global financial crisis. The results from both the HP filter and Running Median Smoothing filter (RMS) showed the output gap to be negative. 


\section{Methodology}

The study period for this paper was 1980 to 2016. Annual time series data were employed in the analyses. The objective of the study was to estimate Namibia's output gap. There are several methods that can be used to estimate the output gap. They include filtering methods, unobservable components models and the production function model. This study uses two conventional approaches, which are the Hodrick-Prescott (HP) filter and production function approach to estimate Namibia's potential output. The potential output was needed to be able to calculate the economy's output gap as deviations from the trend. Potential output is an unobservable variable can only be estimated by using statistical and theoretical methods.

The Hodrick-Prescott (HP) Filter Approach: This is a very common approach in estimating potential output (Jemec, 2012). The HP filter separates trend output from cyclical component of output. The filtering process requires only the actual output series. The process is summarized in equation (1) below.

$$
y_{t, H P}^{*}=\min _{\tau_{t}}\left[\sum_{t=1}^{T}\left(y_{t}-\tau_{t}\right)^{2}+\lambda \sum_{t=2}^{T-1}\left\{\left(\tau_{t+1}-\tau_{t}\right)-\left(\tau_{t}-\tau_{t-1}\right)\right\}^{2}\right]
$$

Where $\tau_{t}$ is, trend component of output $y_{t}$ is actual output and $\lambda$ parameter is constant and is called the smoothing parameter. The smoothing parameter is typically set at 100 for annual data. The HP filter has been found to be preferred in most studies for developing countries because of considerably less data requirements (De Masi, 1997). Despite this advantage, the HP filter suffers from a number of weaknesses. These have been documented by a number of scholars (Harvey \& Jaeger, 1993; De Brouwer, 1998; and Njuguna et al., 2005).

The Production Function Approach: In order to compliment the filtering technique the production function approach is used. The theoretical approach expresses output as a function of factor inputs. The inputs include capital, labour, and the total factor productivity. This study follows Jemec (2012) and Alkhareif and Alsadoun (2016) and use a Cobb-Douglas production function with Hicks-neutral technology which is subject to constant returns:

$Y_{t}=A_{t} K_{t}^{\alpha} L_{t}^{1-\alpha} \quad 0<\alpha<1$

Where, $Y_{t}$ is GDP, $L_{t}$, and $K_{t}$, are the labor and capital inputs, $A_{t}$ is the total factor productivity (TFP) level, $1-\alpha$ is the share of labour in output while $\alpha$ is the share of capital in output. TFP is unobservable, therefore following earlier studies such as Alkhareif and Alsadoun (2016) and Jemec (2012) it is calculated as a Solow residual as follows:

$A_{t}=\frac{Y_{t}}{L_{t}^{1-\alpha} * K_{t}^{\alpha}}$

The estimation of the potential output requires estimates for potential values of total factor productivity, and labour input. These were obtained through a filtering exercise using the HP filter. Potential output was then estimated as in equation (4) below.

$Y_{t}^{*}=A_{t}^{*} L_{t}^{* 1-\alpha} K_{t}^{\alpha}$

Finally, the output gap for the Namibian economy will be determined as follows:

$O G_{t}=\frac{y_{t}-y_{t}^{*}}{y_{t}^{*}} \times 100$

Data: This study uses the real gross domestic product (GDP) as its measure of output. This measure has been used extensively in the literature (Jemec, 2012; Alkhareif \& Alsadoun, 2016). The labour input used in the production function is measured using various data sources. Normally the labour input is measured by the number of hours worked in an economy. However, there is no time series data on working hours for Namibia. The labour input is defined as the number of people employed in the economy, based on the Namibian Labour Force Survey of 2016.The capital input is measured by the amount of fixed capital stock. The data on fixed capital stock is obtained from Namibia Statistics Agency (2017). Capital and Labour income shares are calculated using GDP at factor cost. The average labour income share for Namibia is about 49 percent. It 
therefore follows that the capital share of income is about 51 percent. Historical data on total factor productivity is calculated from Equation (3). The estimate of potential TFP series is obtained from detrending the historical series calculated as a Solow residual.

\section{Potential Output and Output Gap estimates}

HP Filter and Production Function Results: This section presents the estimates for both the potential output and the output gap in Namibia. The potential output series obtained using the HP filter is plotted in Figure 1 together with the actual output series. It is evident that the actual output fluctuated around the potential during the study period. Figure 2 plots the corresponding output gap that was calculated using the potential output obtained from the filtering process. The filtering estimates show periods of negative and positive swings in output gaps during the period under review. The computed estimates show that at independence in 1990 the Namibian economy's output was significantly below its potential level. In the early years of independence, the economy's real GDP surpassed its potential level resulting in a positive output gap of about 6 per cent between 1992 and 1993. During the study period there are three periods in which large negative output gaps were observed: the period between 1983 and 1991, the period between the 1999 and 2003; and then again between 2008 and 2013. During these periods the economy was producing below its capacity.

Figure 1: Potential Output VS Actual Output Figure 2: Output Gap

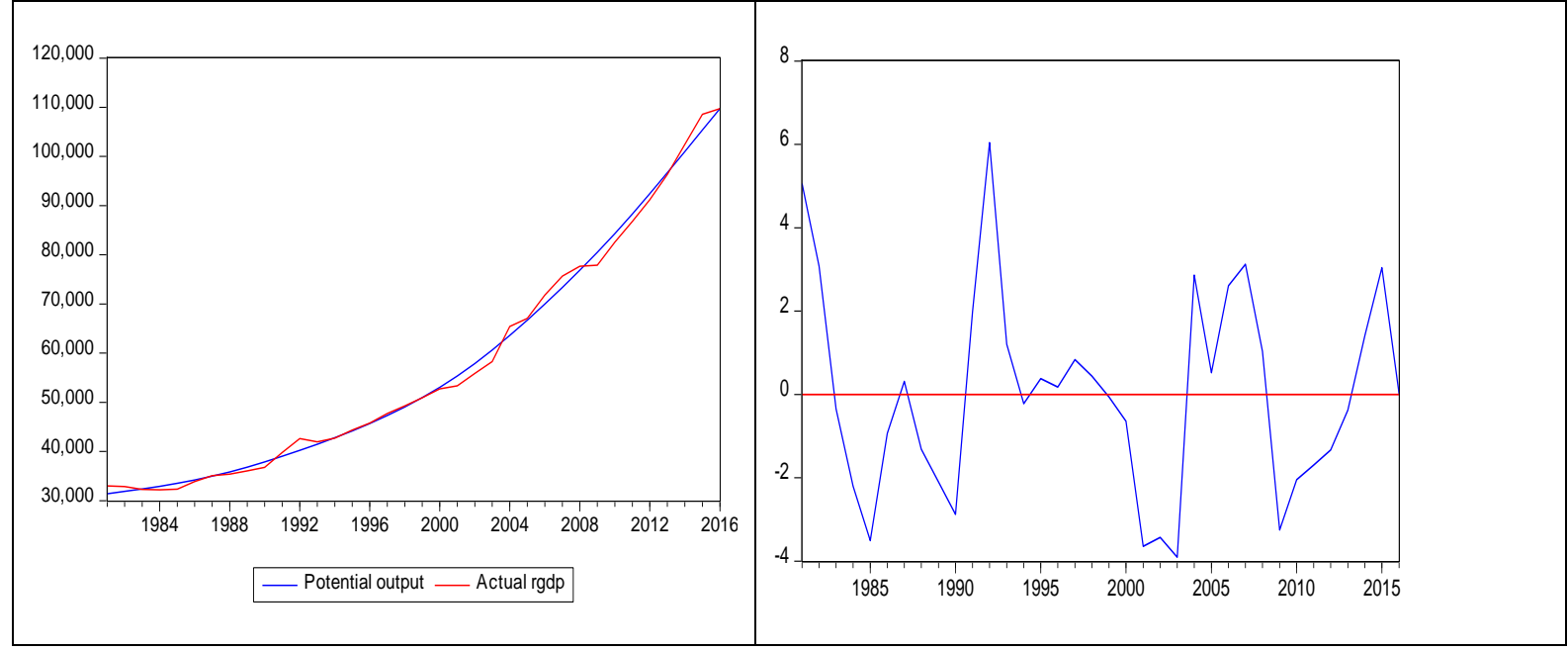

Authors' compilation and values obtained from e views

Figure 3 plots the growth rates in actual and potential output over the study period. The results suggest an annual average growth rate of 3.6 percent for the potential output. It was observed that the growth rate of potential output has been shifting during the period under review. In fact, the results suggest an annual average growth rate at around 1.6 percent "between" 1980 to 1985 and a growth rate of 2.5 percent during the period 1986 to 1990 . The period after independence, the average potential output growth rate was 3.4 percent between 1991 and 1999. The average potential output growth rate was 4.6 percent between 2000 and 2016. 
Figure 3: Actual GDP and Potential GDP Annual Growth Rates

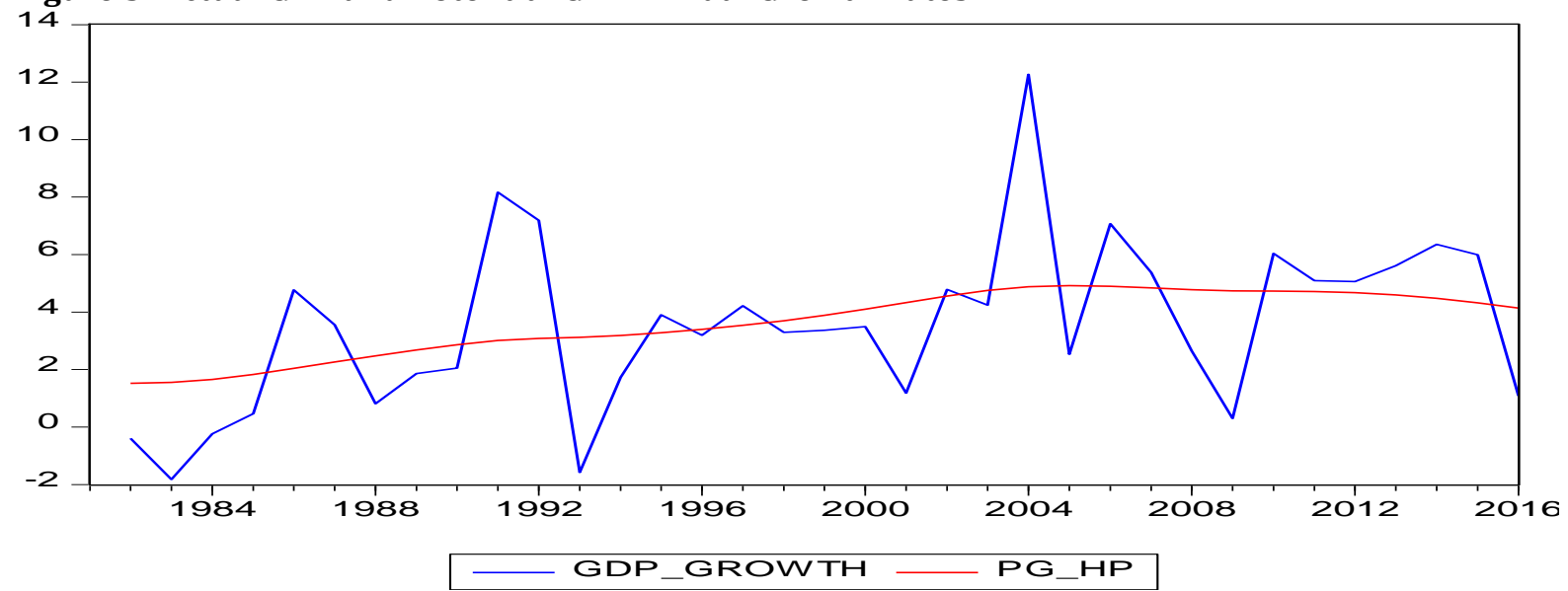

Authors' compilation and values obtained from e views

In the production function approach, the first step was to estimate the total factor productivity series. As pointed out earlier, it is calculated as a Solow residual from a production function. This is summarized in equation (3). The second step was the estimation of the potential values for labour input and total factor productivity using the HP filter. The capital stock is taken to be at its full capacity, hence it was assumed to be at its potential level. Using these potential values of factor inputs together with the factor shares in output, the potential output was estimated according to equation (4). Figure 4 below plots the two potential output series, one estimated using the production function (PRGDP, blue line) and the other estimated using the HP filter method (Potential output, red line) as well as the actual output series (green line). The two series for potential output move very closely over the study period. Both estimates show upward trend in potential output over time. The actual output fluctuated around this trend. Figure 5 plots the two output gap series obtained from the two methods.

\section{Figure 4: Potential Output VS Actual Output Figure 5: Output Gap Using HP Filter VS Production}

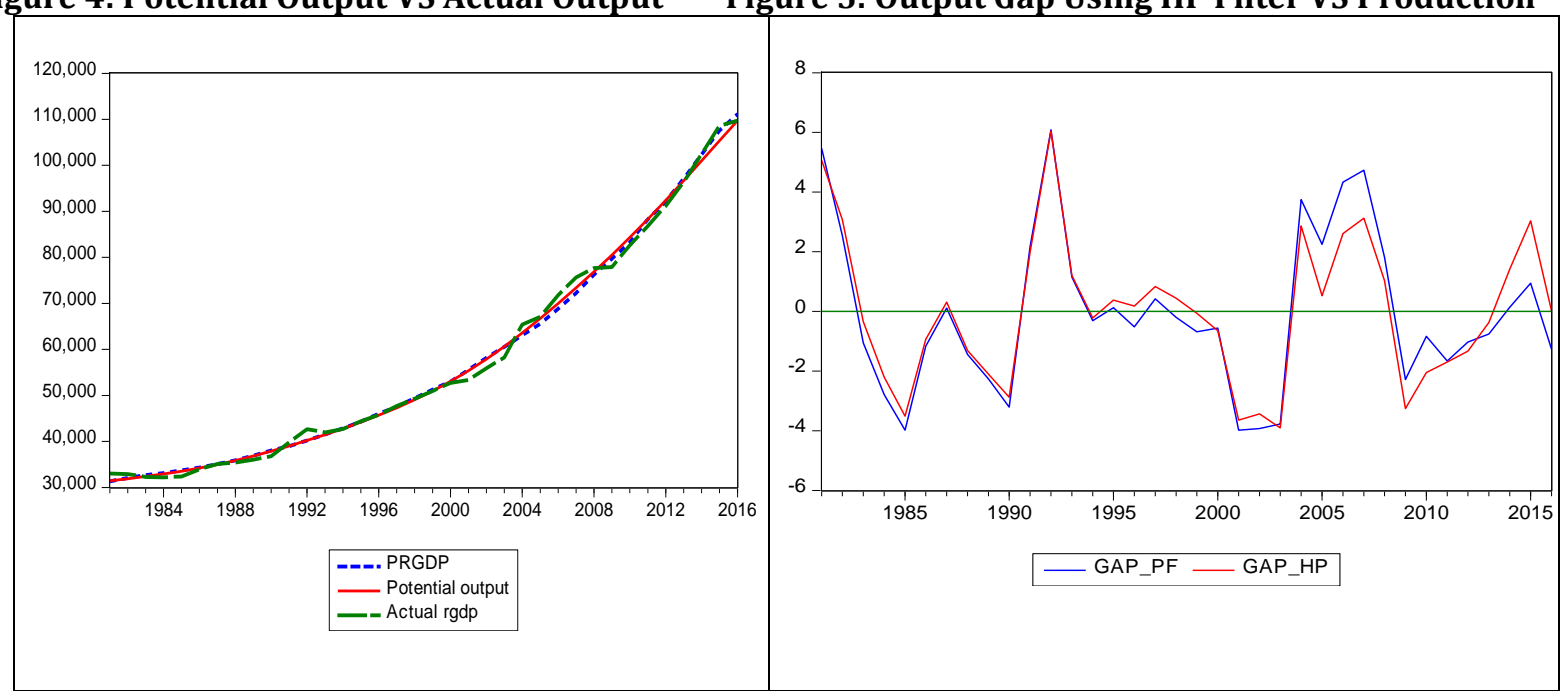

Authors' compilation and values obtained from e views

The two output gaps tend to move together with minor divergences here and there. The production function estimates produce larger positive output gaps than the HP filter method estimates between 2005 and 2008. The estimates from both methods show a similar pattern of negative and positive output gaps over time. The analysis of the output gap estimates from both methods give an indication of whether the economy was underperforming or over performing during the study period. In the 1980s, the period leading to Namibia's independence, negative output gaps can be observed in figure 5. The period after 1990 is characterised by 
remarkable swift economic growth, resulting in positive output gaps. That economic performance can be attributed to the structural changes which were put in place by the then new government. The highest positive output gap of about 6 per cent was observed around 1992. It coincided with an annual growth rate in actual output of about 8 per cent. This observation is in line with what is depicted in figure 3 above. Around 1992 the growth rate is actual output greatly exceeded that of potential output. The negative output gap observed "between" 1998 to 2004 could be attributed to the closure of Tsumeb Corporation Limited mine during 1996 as well as recurrent droughts. The negative output gap observed between 2009 and 2013 can be ascribed to the effects of the global financial crisis of 2007 to 2009.

\section{Conclusion and Policy Recommendations}

The potential growth of the Namibian economy was analysed by estimating potential output and the output gap using two different approaches. The HP filter and the production function approaches were employed. The study used annual time series data for the period 1980 to 2016. The dynamics of the output gaps estimated with the two approaches are fairly similar. On average the output gap was positive in the periods of 1991-1992, 2004-2008, and 2012-2014, and negative otherwise. Well targeted structural reforms are needed in order to improve Namibia's potential output growth rate. These reforms should focus on reducing the structural bottlenecks in the labour market. This can be achieved in a number of ways which include improving access and quality of secondary and tertiary education, vocational and on-the-job training programs. In addition, improving the institutions for labour market dispute resolution will increase market efficiency.

It is important to be cautious when implementing economic policies based on the estimates of the output gap. Such estimates require the estimation of potential output, which is unobservable and requires using different methods to estimate it. Errors in the estimation of the potential output may be carried over the computation of the output gap. The study recommends that a range of indicators of resources strain, such as capacity utilisation and labour shortages, should also be considered in addition to the output gap estimates. Further research should look at different estimation techniques and compare the different results. Namibia has constraint monetary independence to boost or contract the economy due to its membership to the Common Monetary Area (CMA), and thus monetary policy might not be sufficient in boosting the economy during a recession. This is due to the requirement that the Namibian Dollar should be at par with the South African Rand.

Therefore, monetary policy should be used to support the fiscal policy in creating fiscal space and improving the fiscal automatic stabilizers to boost the economy, when the need arises. Examples of automatic fiscal stabilizers include target social transfers and progressive tax systems that increase spending and reduce revenues automatically when economic output slows. In order to reach a deeper understanding of the conclusions and results, the study leaves several open questions that deserve some future research to test their validity as new information becomes available. First, it seems important to consider the possibility of reconciling labour data in Namibia, since results obtained using the production function approach might change. Second, the utilisation of methods other than conventional ones will show if the results and conclusions can be generalized, subject to data availability. Thirdly, linking output gap directly to inflation is beyond the scope of this study and would be beneficial, especially to the central bank, if further research can look into that relationship.

\section{References}

Alkhareif, R. M. \& Alsadoun, N. A. (2016). Estimating the Output Gap for Saudi Arabia. WP/16/1.

Claus, I. (2000). Is the output gap a useful indicator of inflation? Reserve Bank of New Zealand.

De Brouwer, G. (1998). Estimating output gaps. Reserve Bank of Australia: Research Discussion Papers rdp9809.

De Masi, P. R. (1997). IMF Estimates of Potential Output: Theory and Practice. International Monteray Fund: WP/97/177.

Eita, J. H. \& Ashipala, J. M. (2010). Determinants of Unemployment in Namibia. International Journal of Business and Management, 92-104. 
Fedderke, J. W. \& Mengisteab, D. K. (2016). Estimating South Africa's Output Gap Potential Growth Rate. Economic Research Southern Africa, Working Paper 585.

Harvey, A. C. \& Jaeger, A. (1993). Detrending, Stylized Facts and the Business Cycle. Journal of Applied Econometrics, 8, 231-247.

Huang, Y. \& Luo, S. (2017). Potential output and inflation dynamics after the great recession. Empir Econ, 495517.

Jemec, N. (2012). Output Gap in Slovenia what can we learm from different methods? Banka Slovenije.

Jovicic, G. (2017). Estimating Potential Growth and Output Gap in Croatia. Croatian National Bank.

Kanyenze, G. \& Lapeyre. (2012). Growth, employment and decent work in Namibia: A situation analysis. International Labout Organization.

Kasabov, D., Kotseva, P., Vassilev, A. \& Yanchev, M. (2017). Relationship between inflation, potential output and structural unemployment in Bulgaria. Bulgarian National Bank .

Kloudova, D. (2015). Estimating output gap and potential output for Russia and its usefulness by forecasting inflation. International Journal of Economics, 45-59.

Namibia Statistics Agency. (2017). Namibia Labour Force Survey 2016 Report. Windhoek: Namibia Statistics Agency.

Njuguna, A. E., Karingi, S. N. \& Kimenyi, M. S. (2005). Measuring Potential Output and Output Gap and Macroeconomic Policy: The Case of Kenya. University of Connecticut, Economics Working papers.

Podpiera, J., Raei, F. \& Stepanyan, A. (2017). A Fresh Look at Potential Output in Central, Eastern, and Southeastern European Countries. IMF Working paper.

Shahin, H. (2010). Estimation of Egypt's potential output and output gap. Euroindicators working papers, European Union. 